\title{
SISTEM PENDUKUNG KEPUTUSAN UNTUK MENENTUKAN LOKASI PETERNAKAN AYAM BROILER DENGAN METODE PERBANDINGAN EKSPONENSIAL DAN NAIVE BAYES
}

\author{
Ari Wibowo, Anton Setiawan Honggowibowo \\ Jurusan Teknik Informatika \\ Sekolah Tinggi Teknologi Adisutjipto Yogyakarta \\ informatika@stta.ac.id
}

\begin{abstract}
Location is an important role in the success of building a broiler chicken farm. Fault location can be fatal in business continuity. Decision support system is very useful to help help determine the location of broiler chicken farms right. By using the decision support system will give results in the form of value that can be used as a comparison to any alternative location. The method used is Metode Perbandingan Eksponensial (MPE) and Naive Bayes. By using both methods can provide clearer results. Metode Perbandingan Eksponensial is better than the Naive Bayes method, this is because the value generated by the Metode Perbandingan Eksponensial has a contrasting difference in each outcome so as to reduce the refraction that may occur.
\end{abstract}

Keywords: Decision Support System, MPE, Naive Bayes.

\section{Pendahuluan}

Lokasi merupakan sumber daya yang terbatas ketersediaannya, di dunia ini tidak ada suatu tempat yang memiliki kesamaan dengan tempat lainnya. Oleh karena itu keputusan untuk menentukan lokasi peternakan ayam broiler harus diperhitungkan dengan matang. Hal ini sering dilupakan oleh pemula, mereka hanya fokus pada beberapa hal teknis saja seperti perawatan ayam, tidak mengkaji lebih dalam tentanglokasi yang akan dibangun untuk usaha peternakan. Oleh karena itu diperlukan penelitian dengan judul Sistem Pendukung Keputusan Untuk Menentukan Lokasi Peternakan Ayam Broiler Dengan Metode Perbandingan Eksponensial (MPE) dan Naive Bayes.

\section{Metodologi Penelitian}

\subsection{Sistem Pendukung Keputusan}

Sistem pendukung keputusan adalah sebuah sistem terkomputerisasi yang dirancang dan dibangun untuk membantu menyelesaikan masalah yang berkaitan dengan pengambilan keputusan baik di dalam bisnis maupun organisasi. Sistem pendukung keputusan hanyalah sebuah sistem yang menghasilkan sebuah keputusan yang terbaik menurut perhitungan yang ada didalamsistem, akan tetapi pada akhirnya penggunanyalah yang berhak memutuskan alternatif mana yang akan diambil sesuai dengan keperluannya.

\subsection{Metode Perbandingan Eksponensial (MPE)}

Metode perbandingan eksponensial adalah metode yang digunakan dalam sistem pendukung keputusan dengan mengkuantifikasikan pendapat seseorang atau lebih ke dalam skala tertentu untuk menentukan alternatif prioritas keputusan dengan criteria jamak. 
Formulasi untuk perhitungan skor untuk setiap alternatif dalam metode perbandingan eksponensial (Marimin, 2004) adalah :

$\mathrm{m}$

$$
\text { Total nilai }\left(\mathrm{TN}_{\mathrm{i}}\right)=\sum\left(\mathrm{RK}_{\mathrm{ij}}\right)^{\mathrm{TKK}}{ }_{\mathrm{j}}
$$

$\mathrm{j}=1$

Keterangan :

$\mathrm{TN}_{\mathrm{I}} \quad=$ Total nilai alternative ke $\mathrm{i}$.

$\mathrm{RK}_{\mathrm{ij}} \quad=$ Derajat kepentingan relative criteria ke $\mathrm{j}$ pada pilihan keputusanke $\mathrm{i}$.

$\mathrm{TKK}_{\mathrm{j}} \quad=$ Derajat kepentingan criteria keputusan ke-j; TKK $>0$; bulat.

$\mathrm{J}=$ Jumlah pilihan keputusan.

$\mathrm{m}=$ Jumlah criteria keputusan.

\subsection{Metode Naive Bayes}

Metode Naive Bayes yang disederhanakan oleh Prof. Dr. Ir Marimin, M.Scmerupakan salah satu metode yang digunakan untuk analisis dalam pengambilan keputusan terbaik dari beberapa alternatif yang tersedia dengan tujuan menghasilkan keputusan yang optimal. Dalam menentukan keputusan yang paling optimal perlu memperhatikan kriteria-kriteria yang yang mempengaruhinya. Nilai peluang didapat dari suatu informasi awal yang dapat bersifat subjektif maupun objektif.

Persamaan Naive Bayes (Marimin, 2004) yang digunakan untuk menghitung nilai setiap alternatif sering disederhanakan menjadi :

$\mathrm{m}$

$$
\text { Total Nilai }_{\mathrm{i}}=\sum \text { Nilai }_{\mathrm{ij}}\left(\text { Krit }_{\mathrm{j}}\right)
$$

$$
j=1
$$

Keterangan :

Total Nilai $\mathrm{i}_{\mathrm{i}}=$ Total nilai akhir dari alternatif ke-i.

Nilai ${ }_{i j} \quad=$ Nilai dari alternatif ke-i pada criteria ke-j.

Krit $_{\mathrm{j}} \quad=$ Tingkat kepentingan (bobot) criteria ke-j.

i $=1,2,3, \ldots . n ; n=$ Jumlah alternatif.

j $=1,2,3, \ldots \mathrm{m} ; \mathrm{m}=$ Jumlah kriteria.

\subsection{PerancanganPerangkat Lunak}

\subsubsection{Diagram Konteks}

Pada diagram konteks yang ditunjukan pada Gambar1 akan menjelaskan entitas-entitas yang terlibat, dan aliran data secara garis besar. Sehingga dapat dilihat secara keseluruhan input ke sistem atau output dari sistem. Dengan adanya diagram konteks ini dapat diketahui untuk perancangan proses selanjutnya. Untuk aplikasi sistem 
pendukung keputusan dalam menentukan lokasi peternakan ini yang terlibat di dalam sistem adalah user atau pengguna program.

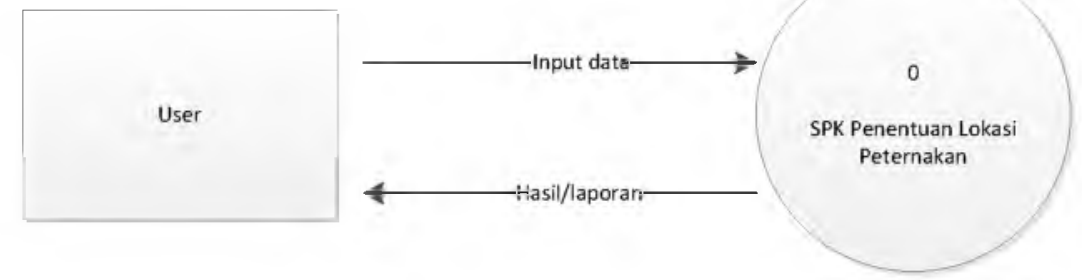

Gambar 1. Diagram Konteks SPK penentuan Lokasi Peternakan Paling Tepat.

\subsubsection{DAD Level 1}

Diagram ini merupakan gambaran rinci dari proses yang dilakukan pada diagram konteks yang hanya menjelaskan secara umum proses yang dikerjakan oleh aplikasi. Proses tersebut digambarkan seperti pada Gambar 2.

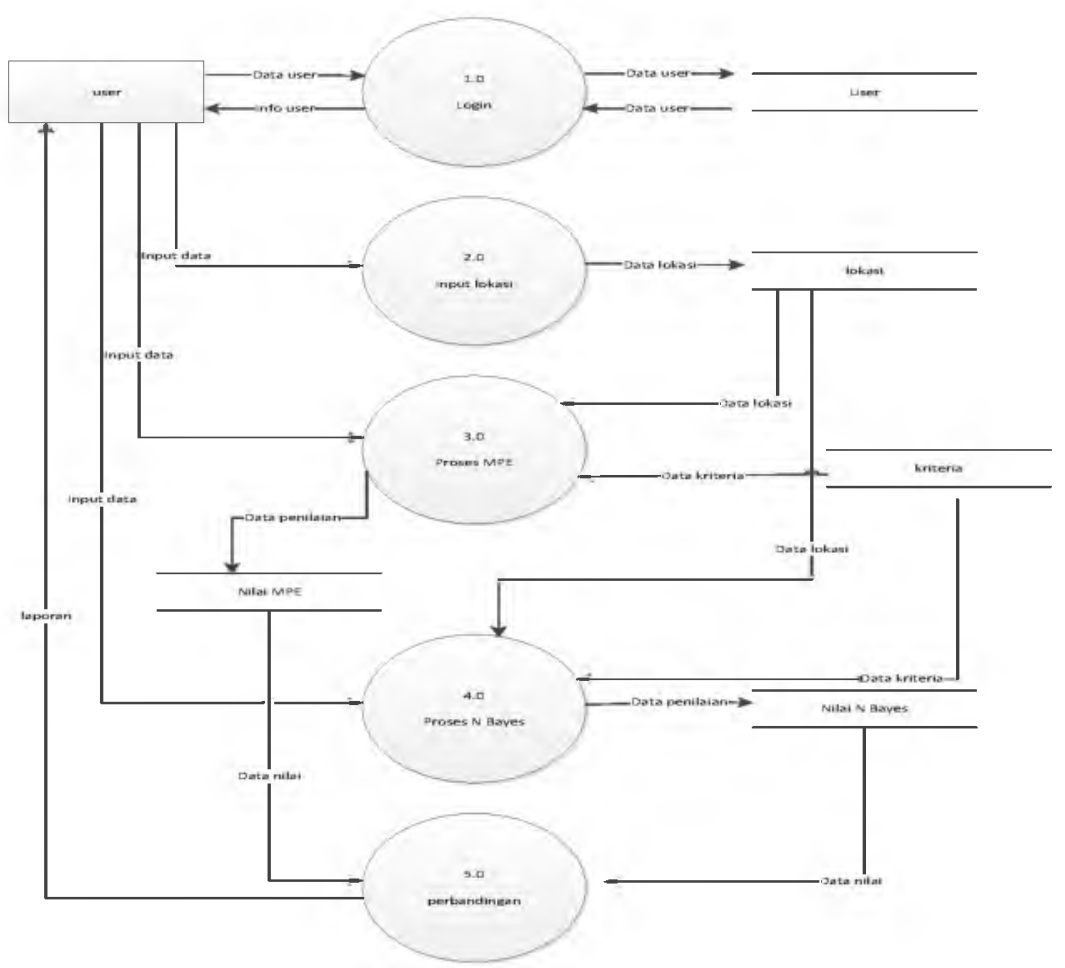

Gambar 2. DAD Level 1

Pada diagram alir data level 1 pada proses 1.0 pengguna atau user login terlebih dahulu menggunakan username dan password yang telah dimiliki, pada proses 2.0 pengguna memasukkan data lokasi yang ingin dinilai dan dibandingkan, data yang telah dimasukkan kemudian disimpan untuk dipanggil lagi pada saat penilaian pada proses 3.0 dan 4.0 kemudian hasil perhitungan dibandingkan untuk memperoleh hasil akhir berupa nilai dan ranking.

\subsubsection{Flowchart Sistem}

Dalam membangun sistem diperlukan flowchart untuk melihat gambaran bagaimana proses dari sistem itu bekerja dari awal hingga selesai, hal ini dimaksudkan agar mengurangi kesalahan yang terjadi jika tidak memiliki acuan dalam rancangan. Sistem ini juga memilikia lur data seperti yang ditunjukkan pada Gambar3. 


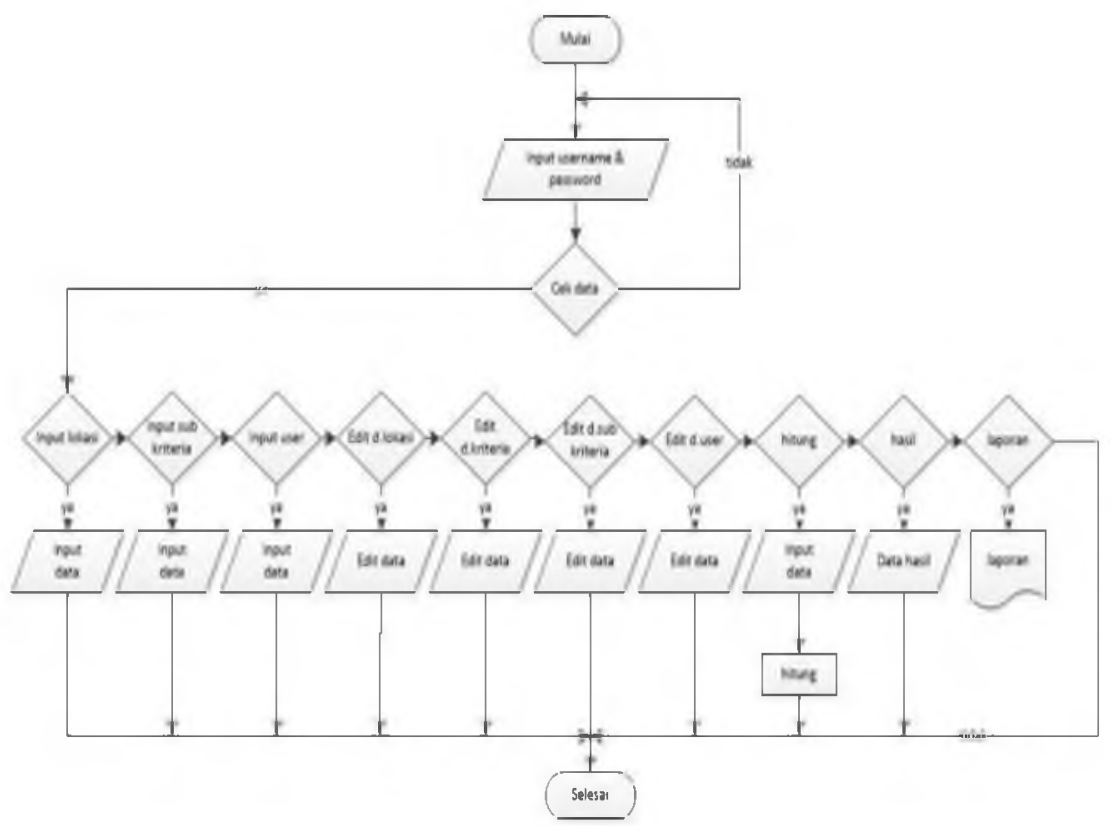

Gambar 3. Flowchart Sistem

\subsubsection{Relasi Database}

Relasi database adalah hubungan antar tabel yang ada pada suatu database, yang disebut relasi adalah tabel yang berdiri atas baris dan kolom. Kumpulan relasi-relasitersebut yang membentuk sebuah database. RelasidatabasepadaaplikasiinidapatdilihatpadaGambar4.

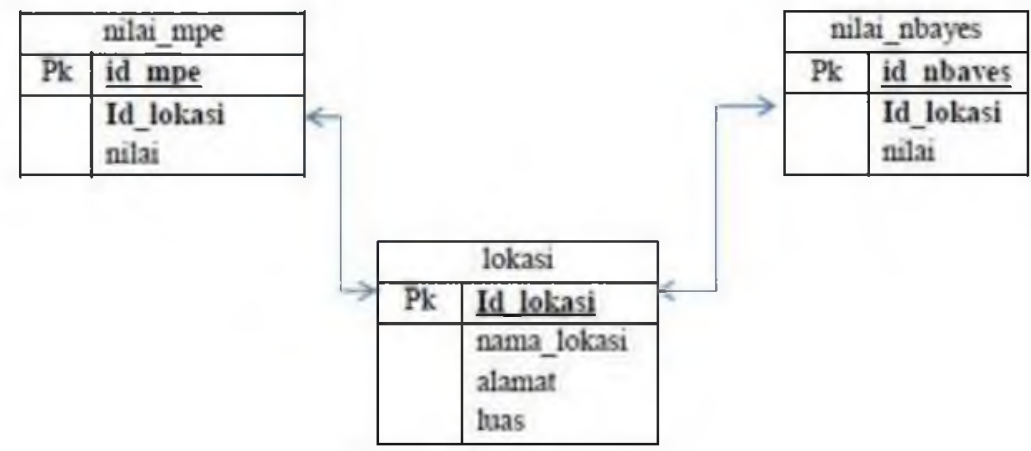

Gambar 4. Relasi Database

\subsubsection{PerancanganAntarMuka}

Rancangan halaman input data lokasi berguna untuk menyimpan data lokasi yang akan dilakukan penilaian. Pengguna memasukkan nama lokasi, bisa menggunakan nama pemilik lokasi maupun nama daerah lokasi, kemudian memasukkan alamat lokasi dan luas lokasi.

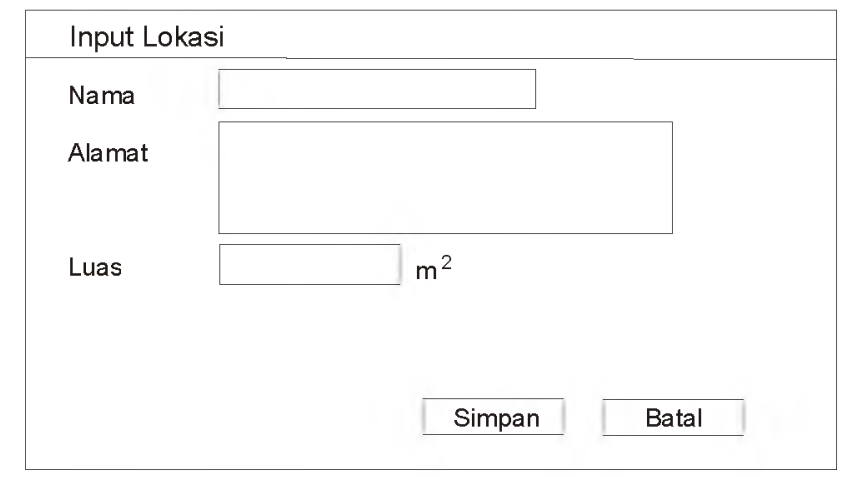


Gambar 5. Rancangan Tampilan Input Data Lokasi.

Rancangan tampilan halaman hitung ini digunakan untuk memasukkan atau memberikan penilaian terhadap lokasi. Pertama pengguna memilih lokasi yang akan diberikan penilaian, setelah menentukan lokasi mana yang akan dinilai pengguna melakukan penilaian dengan menjawab kriteria-kriteria yang telah ditentukan.

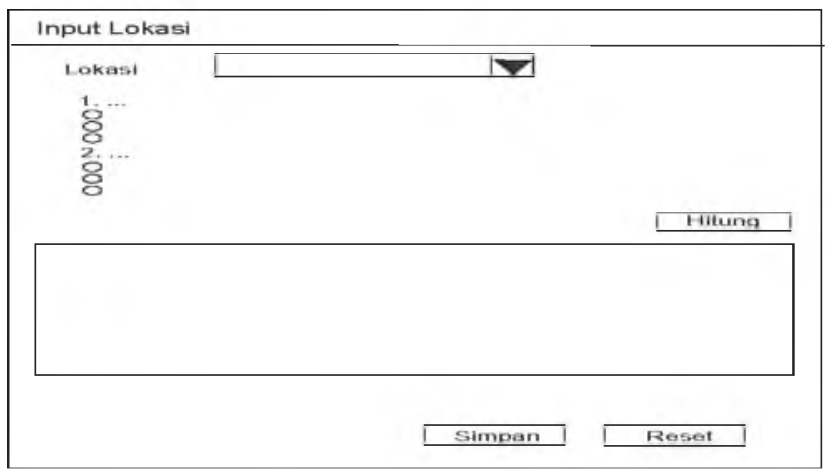

Gambar 6.Rancangan Tampilan Hitung.

Rancangan tampilan halaman hasil digunakan untuk menampilkan data hasil perhitungan dari beberapa lokasi yang telah disimpan. Data hasil perhitungan ditampilkan berdasarkan metode yang digunakan, dari masing-masing metode menghasilkan nilai yang dijadikan referensi bagi pengguna untuk mengambil keputusan.

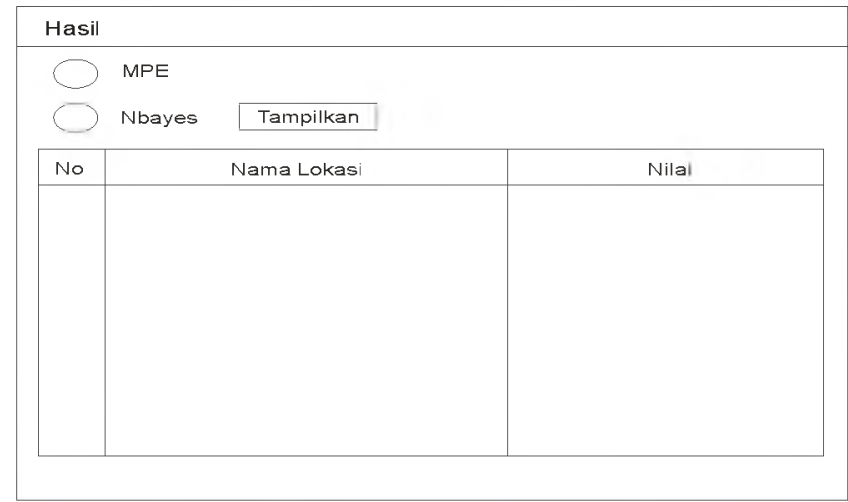

Gambar 7. Rancangan Tampilan Hasil.

\section{Hasil Dan Pembahasan}

\subsection{Hasil}

Pada tampilan halaman utama merupakan tampilan awal setelah pengguna berhasil melakukan login. Di halaman utama ini hanya terdapat main menu dan gambar sebagai variasi agar tampilan tidak membosankan. 


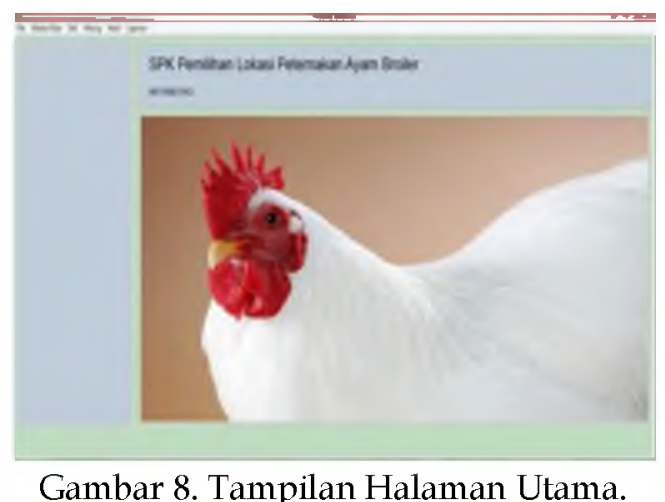

Pada halaman input lokasi terdapat beberapa kolom yang digunakan untuk melakukan input data lokasi yang akan dilakukan penilaian. Data lokasi yang telah di-input-kan akan disimpan untuk kemudian dipanggil kembali pada saat pemilihan lokasi yang akan dinilai. Tampilan halaman input lokasi dapat dilihat pada Gambar 9.

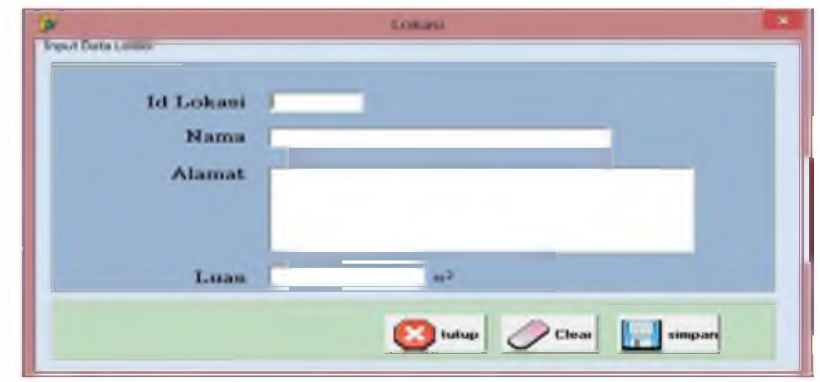

Gambar 9.Tampilan Halaman Input Lokasi.

Pada tampilan halaman hitung digunakan untuk melakukan penilaian terhadap lokasi yang diinginkan dengan memilih alternatif pilihan pada setiap kriteria.

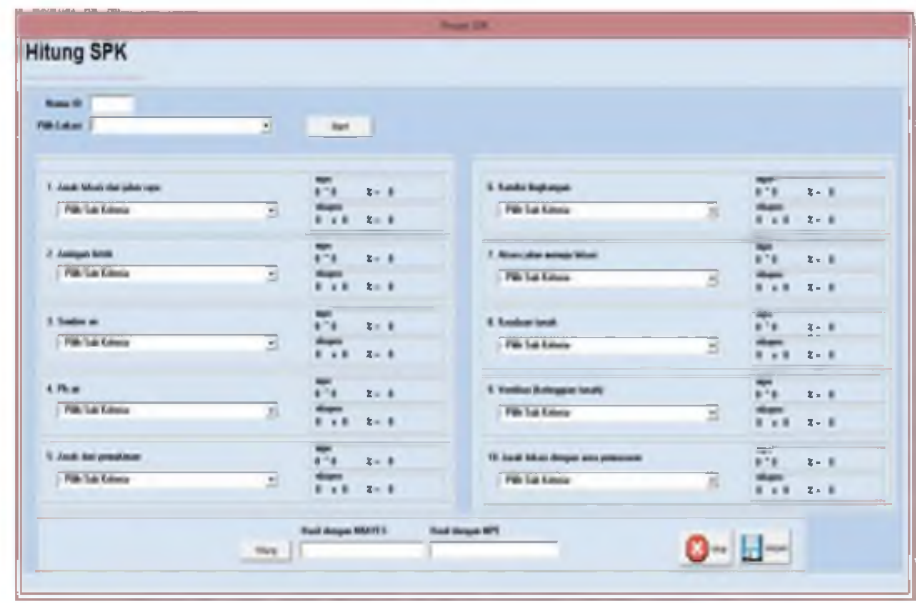

Gambar 10. Tampilan Halaman Hitung. 


\subsection{Pembahasan}

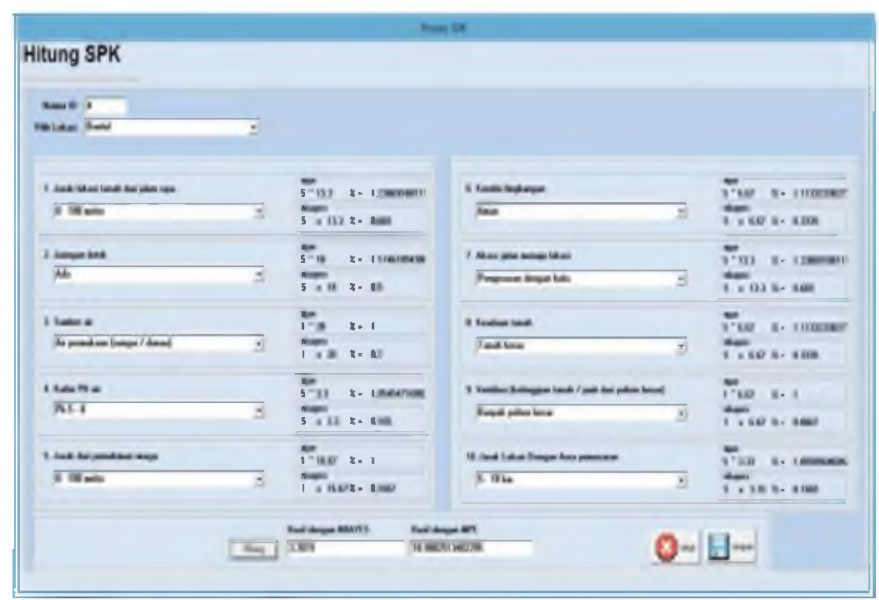

Gambar 11. Tampilan Halaman Perhitungan.

Pada halaman perhitungan pengguna mengisi data-data yang diperlukan untuk perhitungan. Setelah data telah diisi semua pengguna dapat melakukan perhitungan.

Tabel 1. Perbandingan Hasil Perhitungan Metode MPE.

$\begin{array}{llll}\text { No } & \text { Nama Lokasi } & \begin{array}{c}\text { Perhitungan } \\ \text { Manual }\end{array} & \text { PerhitunganAplikasi } \\ 1 & \text { Bantul } & 10.9879 & 10.9882513402295 \\ 2 & \text { GunungKidul } & 10.8502 & 10.8513306125507 \\ 3 & \text { Wates } & 10.799 & 10.7992509427552\end{array}$

Tabe12. Perbandingan Hasil Perhitungan Metode Naive Bayes

$\begin{array}{clcc}\text { No } & \text { NamaLokasi } & \begin{array}{c}\text { Perhitungan } \\ \text { Manual }\end{array} & \begin{array}{c}\text { Perhitungan } \\ \text { Aplikasi }\end{array} \\ 1 & \text { Bantul } & 3.2619 & 3.2619 \\ 2 & \text { GunungKidul } & 2.5984 & 2.5985 \\ 3 & \text { Wates } & 2.532 & 2.5314\end{array}$

\section{Penutup}

\subsection{Kesimpulan}

Kesimpulan yang diperoleh dari penelitian yang telah dilakukan adalah

1. Aplikasi Sistem Pendukung Keputusan Penentuan Lokasi Peternakan Ayam Broiler dengan menggunakan Metode Perbandingan Eksponensial dan Naive Bayes telah berhasil dibuat dan dapat menghasilkan perankingan data lokasi.

2. Perbandingan lokasi dengan menggunakan kedua metode memberikan hasil nilai yang dapat dijadikan sebagai acuan dalam memilih lokasi.

3. Pada kasus tugas akhir ini Metode Perbandingan Eksponensial lebih baik dibandingkan dengan metode Naive Bayes, hal ini dikarenakan nilai yang dihasilkan oleh Metode Perbandingan Eksponensial memiliki perbedaan yang kontras di setiap hasilnya sehingga dapat mengurangi bias yang mungkin terjadi.

\subsection{Saran}

Saran untuk penelitian selanjutnya berdasarkan hasil penelitian ini adalah 
1. Sistem perlu dibandingkan lagi menggunakan metode perangkingan yang berbeda pola algoritmanya sehingga dapat diketahui kinerjanya.

2. Sistem dapat dikembangkan untuk menilai bagaimana sebuah lokasi ideal yang dihasilkan oleh sistem berpengaruh terhadap produksi dan keuntungan.

\section{Daftar Pustaka}

Fadilah, Roni. 2013. Super Lengkap Beternak Ayam Broiler. Jakarta : Agromedia Pustaka.

JogiyantoMH. 2005. Analisis dan Desain Sistem Informasi. Yogyakarta : Andi Offset.

Kadir, Abdul. 2009. DasarPerancangandanImplementasi Database Relasional.Yogyakarta :Andi Offset.

Kadir, Abdul. 2005. Pemograman Database dengandelphi 7 menggunakanAccesdan ADO. Yogyakarta :Andi Offset.

Marimin. 2005. TeknikdanAplikasiPengambilanKeputusanKriteriaMajemuk. Jakarta :Grasindo.

Onggo.2013. Sistem Pendukung Keputusan Untuk Pemilihan Lokasi Pembukaan Cabang Usaha Variasi Mobil Dengan Metode Promethee. Jurnal Sarjana Teknik Informatika, Vol 1, No 1 (2013).http:/portalgaruda.org/?ref=browse\&mod=viewarticle\&article=12365010. Juni 2014.

Rangkuti, Haris.2011. Teknik Pengambilan Keputusan Multi Kriteria Menggunakan Metode Bayes, Mpe, Cpi Dan Ahp. Jurnal ComTech, Vol 2, No1, (2011). http://www.qiournal.co.id/paper1043-teknik-pengambilan-keputusan-multi-kriteria-menggunakan-metode-bayes-mpe-cpi-danahp.html. Juni 2014.

Sunaryo.2014. SistemPendukungKeputusanuntukInvestasiPerumahan Area Malang MenggunakanAlgoritma Bayesian.Jurnal EECCIS Vol 8, No 1, Juni2014.http://iurnaleeccis.ub.ac.id/index.php/eeccis/article/oiew/230/203.Juni 2014.

Turban, dkk. 2005. Decision Support Systems and Intelligent Systems (Sistem Pendukung Keputusan dan Sistem Cerdas). Yogyakarta: Andi Offset. 
SISTEM PENDUKUNG KEPUTUSAN UNTUK MENENTUKAN LOKASI PETERNAKAN AYAM BROILERDENGAN METODE PERBANDINGAN EKSPONENSIAL DAN NAIVE bAYES 